\title{
Purification of single-walled carbon nanotubes
}

\author{
A. Yaya ${ }^{1}$, C.P. Ewels ${ }^{1, a}$, Ph. Wagner ${ }^{1}$, I. Suarez-Martinez ${ }^{2}$, A. Gebramariam Tekley ${ }^{3}$, and L. Rosgaard Jensen ${ }^{4}$ \\ 1 IMN, CNRS UMR 6502, Université de Nantes, 2 rue de la Houssinière, BP 32229, 44322 Nantes, France \\ 2 Nanochemistry Research Institute, Curtin University of Technology, GPO Box U1987, Perth 6845, Western Australia \\ 3 Chemistry Department, Science Faculty, Hawassa University, P.O. Box 5, Addis Ababa, Ethiopia \\ 4 Department of Mechanical and Manufacturing Engineering, Aalborg University, Pontoppidanstraede 105, 9220 Aalborg East, \\ Denmark
}

Received: 3 December 2010 / Accepted: 7 January 2011

Published online: 13 April 2011 - (C) EDP Sciences

\begin{abstract}
We present a study of purification of single-walled carbon nanotubes (SWCNTs) using different oxidation temperatures and chemical treatments. We have developed a simple two annealing-steps procedure resulting in high nanotube purity with minimal sample loss. The process involves annealing the SWCNTs at $300{ }^{\circ} \mathrm{C}$ for $2 \mathrm{~h}$ with subsequent reflux in $6 \mathrm{M} \mathrm{HCl}$ at $130{ }^{\circ} \mathrm{C}$, followed by further annealing at $350{ }^{\circ} \mathrm{C}$ for $1 \mathrm{~h}$ with reflux in $6 \mathrm{M} \mathrm{HCl}$ at $130{ }^{\circ} \mathrm{C}$. The process results in effective removal of carbon impurities and metal particles which are associated with SWCNTs production. The process is less time consuming (complete in $4.5 \mathrm{~h}$ ) than conventional acid purification methods which require over $5 \mathrm{~h}$, and less destructive than conventional methods with a yield of $26 \%$. SWCNT purity was assessed using Raman spectroscopy, thermogravimetry and scanning electron microscopy coupled with energy-dispersive X-ray spectroscopy.
\end{abstract}

\section{Introduction}

The landmark paper by Iijima and Ichihashi in 1993 [1] showing single-walled carbon nanotubes (SWCNTs) marked a new beginning for a wide range of research in the field of nanotechnology due to their potential for various applications such as electronic devices, nanocomposites, supercapacitors $[2,3]$ and secondary batteries $[4,5]$. Common production methods for these versatile materials is by chemical vapour deposition $[6]$, arc-discharge $[7,8]$ and laser vaporisation [9], in the presence of a metal catalyst. Both of these production methods result in a final product containing impurities, and since high purity nanotubes are essential for final applications in, e.g. electronics, a purification process has to be employed.

Several approaches have been developed for purifying SWCNTs, but often with little success or low yield in the final samples. Techniques such as gas phase or thermal annealing in air or oxygen has been used [10-12] in order to remove amorphous carbons and other carbon nanoparticles such as fullerenes that are found in SWCNT soot. In addition, liquid-phase reactions in various acids or corrosive solvents [13-18] have been used to remove the metal catalysts required from the synthesis of SWCNTs. Other purification techniques include ultrasonication, centrifugation, and filtration $[19,20]$. The above mentioned techniques are rarely used exclusively to purify the SWCNTs, and instead are more common in combination.

\footnotetext{
a e-mail: chris.ewels@cnrs-imn.fr
}

Ebbesen et al. in 1994 purified nanotubes produced by the arc-discharge method using oxidizing gases to selectively attack the nanotubes caps [11]. This approach relies on the fact that nanoparticles containing defect-rich structures oxidize more easily than perfect nanotubes. Chiang et al. purified SWCNTs produced by laser vaporisation by treating the SWCNTs in nitric acid, with the aim of dissolving the metal catalyst [12]. This was then followed by two oxidation steps, first at $300{ }^{\circ} \mathrm{C}$ and at $500{ }^{\circ} \mathrm{C}$ using an $\mathrm{HCl}$ extraction step after each oxidation. Moon et al. [21] thermally annealed SWCNT powder at $470{ }^{\circ} \mathrm{C}$ in air for $50 \mathrm{~min}$, followed by treatment with $\mathrm{HCl}$ for $24 \mathrm{~h}$. This resulted in a final reported yield of $25 \mathrm{wt} . \%$ compared to the initial product. Hou et al. [22] combined a purification process consisting of bromination and subsequent selective oxidation with oxygen at $530{ }^{\circ} \mathrm{C}$ for 3 days with a reported purity of the final product of $75 \mathrm{wt} . \%$. Chen et al. reported a purity of 90 wt.\% from their work, using chlorine water and hydrogen chloride gas mixtures to remove amorphous and spherical carbon particles with or without metal catalyst inside [23].

Oxidation methods can destroy the nanotubes along with the impurities, which was attributed to the metal catalyst present in the as-produced SWCNTs [24], since in the presence of the oxidizing gases the metal particles catalyse low temperature oxidation of carbons. Other nondestructive procedures via organic functionalization [25] have been developed which render the SWCNTs more soluble than impurities by attaching functional groups to the 
nanotubes, allowing separation by filtration or chromatography [26]. However the functional moiety attached to the tubes then needs to be removed.

In this paper, we examine different purification procedures for the removal of carbon nanoparticles and metal catalyst in SWCNTs samples. We propose an optimal procedure for cleaning SWCNTs consisting of a two annealing step process with high final purity and minimal loss of SWCNTs.

\section{Method}

The as-prepared SWCNTs were arc-discharge produced and supplied by Carbolex Inc. According to the supplier's information, the purity of the sample was 50-70 vol.\% [27]. The average nanotube diameter was $1.4 \mathrm{~nm}$ and typically grouped in bundles of about $\sim 20 \mathrm{~nm}$ in diameter. Impurities include approximately 35 wt.\% residual catalyst $(\mathrm{Ni}, \mathrm{Y})$ and amorphous carbon on the outer surfaces of the bundles.

Gas phase oxidation was done using atmospheric air to make the process as simple as possible. The oxidation temperature (annealing temperature in our case) ranges from $200{ }^{\circ} \mathrm{C}$ to $550{ }^{\circ} \mathrm{C}$. Although the annealing (oxidation) time can be as long as $5 \mathrm{~h}$ and the temperature as high as $800{ }^{\circ} \mathrm{C}$, shorter times and lower oxidation temperatures are preferred to reduce the nanotube degradation. Gas phase oxidation is followed by acid treatment for a number of times. The details of the compared procedures are as follows:

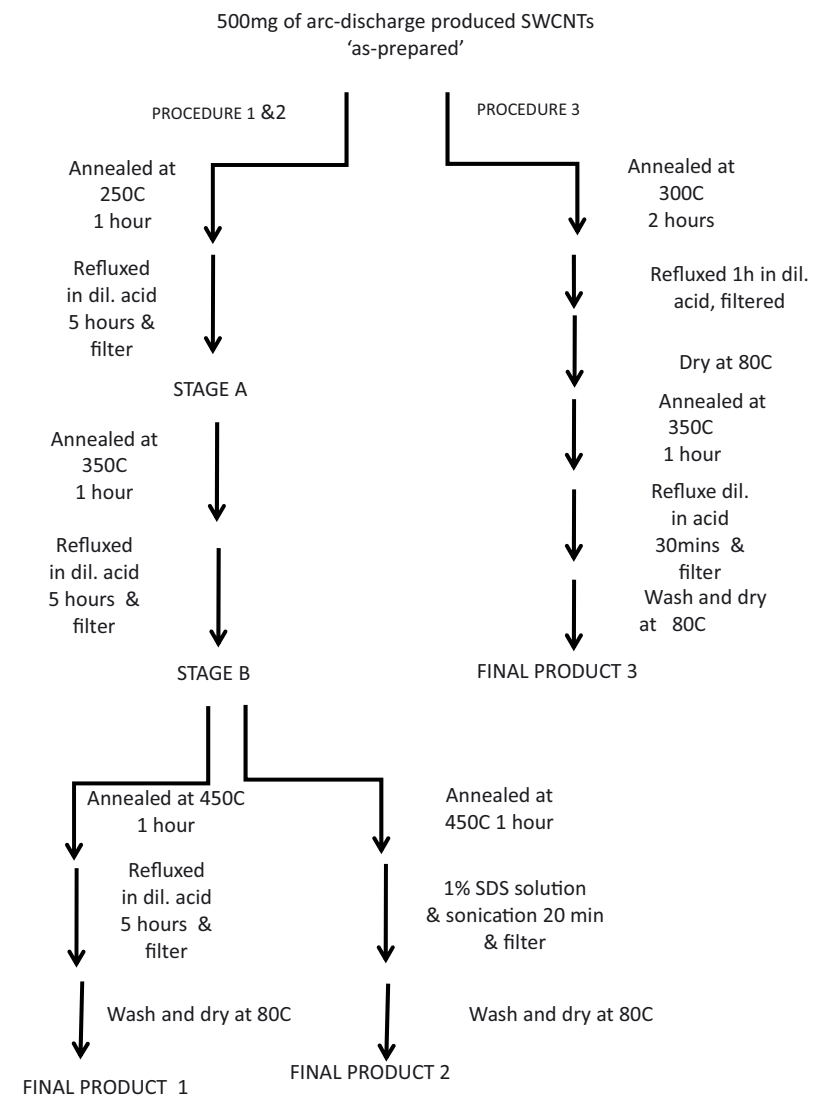

\subsection{Procedure $1[\mathrm{P} 1]$}

This procedure consists of a multi-step process of four cycles which includes a series of annealing and refluxing steps. $500 \mathrm{mg}$ of the SWCNTs were annealed in a furnace at $250{ }^{\circ} \mathrm{C}$ for one hour, expecting to remove some of the non tubular forms of carbon. After cooling, the sample was refluxed in $200 \mathrm{~mL}$ of $4 \mathrm{M} \mathrm{HCl}$ at $100{ }^{\circ} \mathrm{C}$ for about $5 \mathrm{~h}$ in order to dissolve soluble impurities and metals (usually $\mathrm{Ni}$ and Y). The solution was then filtered using a Millipore membrane filter with pore size $0.45 \mu \mathrm{m}$, and the filtrate was washed with distilled water. This helps separate the soluble impurities from the carbon nanotubes. After this first cycle of filtration, the second annealing is completed at $350{ }^{\circ} \mathrm{C}$ for an hour followed by reflux with $4 \mathrm{M} \mathrm{HCl}$ and filtration. A third cycle of purification was done by annealing the sample at $450{ }^{\circ} \mathrm{C}$. Finally the filtered and washed SWCNTs were dried at $80{ }^{\circ} \mathrm{C}$ and weighed to determine the yield. We also investigated the use of $\mathrm{HNO}_{3}$ instead of $\mathrm{HCl}$.

\subsection{Procedure $2[\mathrm{P} 2]$}

This procedure follows the same first two cycles as P1, while the third cycle is modified. After annealing and acid treatment at $450{ }^{\circ} \mathrm{C}$, the mixture was dispersed in $1 \%$ sodium dodecyl sulphate (SDS) solution (500 mg of the purified SWCNTs in $250 \mathrm{~mL}$ of $1 \%$ SDS solution). This solution was sonicated for about $20 \mathrm{~min}$ to obtain a well dispersed solution. The solution was filtered using $0.45 \mu \mathrm{m}$ membrane filter and washed with ethanol and deionised water respectively. Finally, the filtrate was dried at $80^{\circ} \mathrm{C}$.

\subsection{Procedure $3[\mathrm{P} 3]$}

This procedure is a two step process where the SWCNT material is annealed at $300{ }^{\circ} \mathrm{C}$ for two hours with subsequent reflux using $6 \mathrm{M} \mathrm{HCl}$ at $130{ }^{\circ} \mathrm{C}$. After drying the material in an oven at $80{ }^{\circ} \mathrm{C}$, the sample was further annealed at $350{ }^{\circ} \mathrm{C}$ for another one hour and then refluxed with $6 \mathrm{M} \mathrm{HCl}$ at $130{ }^{\circ} \mathrm{C}$. Finally the sample was dried at $80{ }^{\circ} \mathrm{C}$.

Raman spectroscopy of the resultant samples was performed using a Renishaw 1000 system with a $785 \mathrm{~nm}$ laser. A Zeiss $1540 \mathrm{XB}$ scanning electron microscope (SEM) equipped with energy-dispersive X-ray spectroscopy (EDS) was used to examine the samples. Thermo-gravimetric analysis (TGA) and differential thermo-gravimetric (DTG) were performed using a Netzsch TG instrument Model STA 409 PC.

\section{Results and discussion}

Generally the as-produced SWCNTs contain two types of impurities: transition metal catalyst particles (typically $\mathrm{Ni}$ and $\mathrm{Y}$ ) and carbonaceous species, which include amorphous carbon, fullerenes, multishell carbon nanocapsules, 
A. Yaya et al.: Purification of single-walled carbon nanotubes

Table 1. Weight loss of SWCNTs samples during purification process using Procedures 1 and 2, calculated with respect to the weight of sample obtained in the previous step. Figures in brackets show total percentage weight loss by this step as a function of initial sample weight. Both purification processes result in loss of about two thirds of the initial sample weight.

\begin{tabular}{|c|c|c|c|}
\hline & Oxidation temperature $\left[{ }^{\circ} \mathrm{C}\right]$ & Resultant weight loss [\%] & Main processes \\
\hline First cycle & 250 & $23(23)$ & $\begin{array}{l}\text { Oxidation in air followed by } \\
\text { reflux with } 4 \mathrm{M} \mathrm{HCl}\end{array}$ \\
\hline Second cycle & 350 & $51(62)$ & $\begin{array}{l}\text { Oxidation in air followed by } \\
\text { reflux with } 4 \mathrm{M} \mathrm{HCl}\end{array}$ \\
\hline Third cycle & $\begin{array}{l}450 \\
450\end{array}$ & $\begin{array}{c}9(66) \\
15.5(68)\end{array}$ & $\begin{array}{l}\text { (P1) Oxidation in air } \\
\text { (P2) Oxidation in air followed by } \\
\text { reflux with } 4 \mathrm{M} \mathrm{HCl} \text { and then } \\
\text { dispersing in SDS solution by sonication }\end{array}$ \\
\hline
\end{tabular}

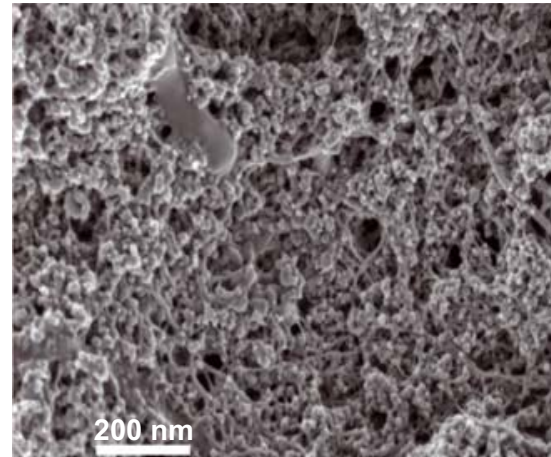

(a)

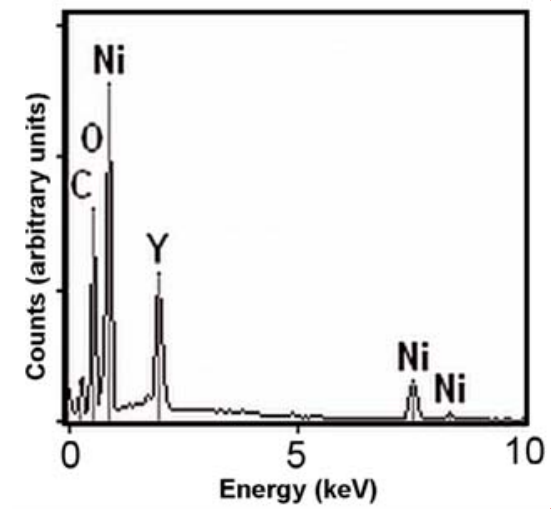

(b)

Fig. 1. Representative (a) SEM image and (b) EDS spectrum of as-produced SWCNTs showing the presence of Ni and $\mathrm{Y}$ catalyst in the sample as well as oxygen impurities.

and nanocrystalline graphites. Figure 1 shows a representative SEM image and EDS spectra of as-produced SWCNTs where the major impurities can be identified qualitatively.

Oxidation of the as-produced SWCNTs at $250{ }^{\circ} \mathrm{C}$ showed significant weight loss (Tab. 1), which shows the loss of carbonaceous materials. This gas phase oxidation is carried out prior to liquid phase oxidation in order to remove the carbonaceous impurities and amorphous carbon which surrounds the metal impurities and to expose the metals for chemical attack during chemical oxidation. It helps to remove amorphous carbon by oxidizing the amorphous carbon species to carbon oxides, and also converts the metal-containing catalyst particles into metal oxides and hydroxides. This process of oxidation later promotes further cracking and fracturing of the carbon encapsulation on the metal surface.

Acid treatment $(4 \mathrm{M} \mathrm{HCl})$ of these samples also caused some weight loss, mainly due to removal of the metal catalysts. Acid reflux in $4 \mathrm{M} \mathrm{HCl} \mathrm{results} \mathrm{in} \mathrm{a} \mathrm{solution} \mathrm{of} \mathrm{green-}$ ish colour indicative of metal chlorides and metal oxides, showing successful significant removal of metal catalysts, as discussed above. Since the metal is insoluble in water and remains with the solute during filtration, further oxidation helps in removing the remaining metals.

Chemical reaction with $\mathrm{HCl}$ yields metal chlorides which are soluble in water. Normally, halogen-containing acids such as $\mathrm{HCl}, \mathrm{HF}, \mathrm{HI}$ and $\mathrm{HBr}$ result in soluble metal halides by reaction between the halogen-containing acid and metal, and the metal halides can be removed by washing with water. The $\mathrm{HCl}$ oxidant can also etch the carbon shell that has been weakened by the gas phase oxidation causing the metal catalysts to oxidize to their corresponding metal oxide (hydroxide). This is manifested by an increase in volume resulting in cracks and openings on the carbon coating. Generally, the oxidation process can be represented by the scheme:

$$
\begin{aligned}
2 \mathrm{HCl}+\mathrm{M}+\mathrm{C} & (\text { amorphous carbon })+2 \mathrm{O}_{2}(\text { air }) \\
& \rightarrow \mathrm{MCl}_{2}(\text { soluble })+\mathrm{CO}_{2}+\mathrm{H}_{2} \mathrm{O}+\mathrm{MO}
\end{aligned}
$$

where $\mathrm{M}$ is the metal catalyst $(\mathrm{Y}, \mathrm{Ni})$ present in the pristine SWCNTs.

We have investigated the effect of using concentrated $\mathrm{HNO}_{3}$ instead of $\mathrm{HCl}$. However in this case sample damage was increased, and indeed by the end of the procedure the sample vanished completely due to successive exposure to oxidation by heat and acid. Although the use of $\mathrm{HNO}_{3}$ acid is known to purify raw nanotubes [28], the low final yield ( $\sim 3.8$ wt.\%, as indicated in Tab. 2$)$ obtained from this procedure shows that $\mathrm{HNO}_{3}$ introduces significantly more defects on the surface of the nanotubes than $\mathrm{HCl}$ treatment, which facilitates their subsequent destruction during oxidation due to loss of structural integrity. 


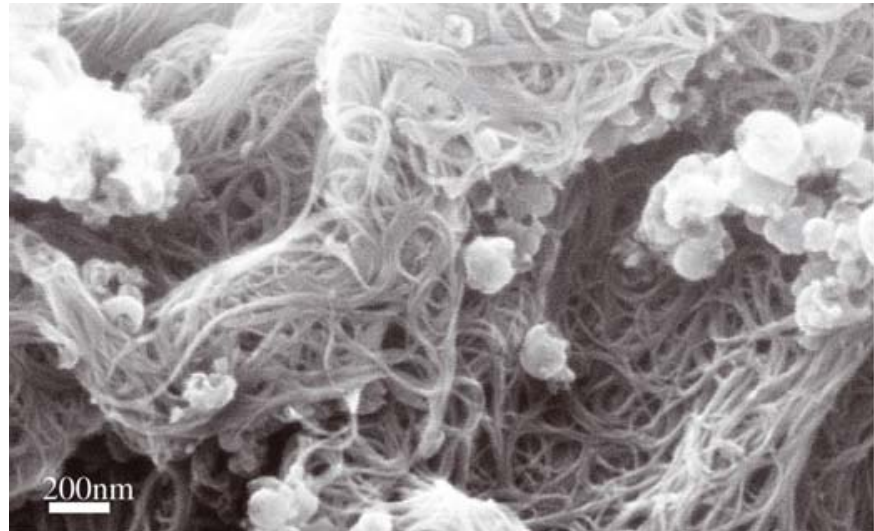

Fig. 2. SEM image of SWCNTs after annealing at $250{ }^{\circ} \mathrm{C}$ and reflux in $4 \mathrm{M} \mathrm{HCl}$ (Stage $\mathrm{A}$ ).

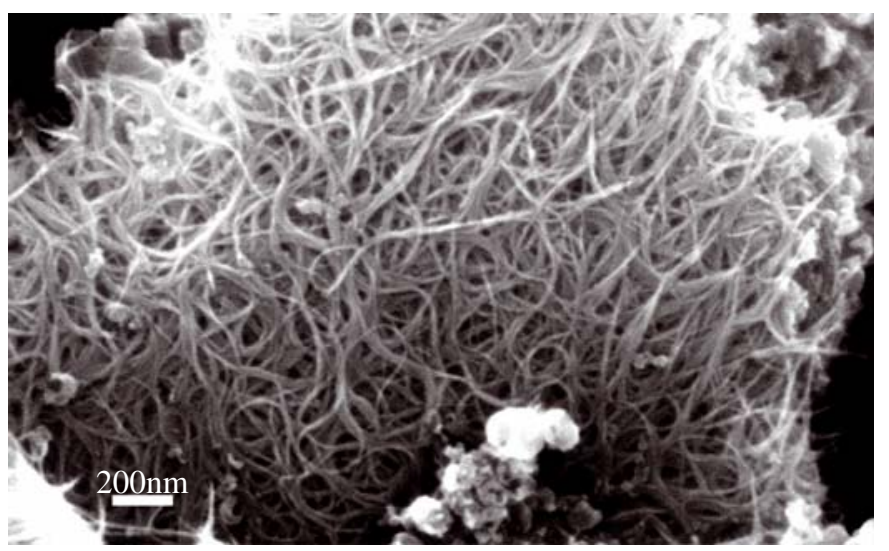

Fig. 3. SEM image of purified SWCNTs after the secondary oxidation at $350{ }^{\circ} \mathrm{C}$ followed by reflux with $4 \mathrm{M} \mathrm{HCl}$ (Stage B).

Table 2. Final sample yield (\%) after different purification procedures (see text).

\begin{tabular}{lc}
\hline Purification procedure & Yield (\%) \\
\hline P1 & 18 \\
P2 & 10 \\
P3 & 26 \\
P1 with $\mathrm{HNO}_{3}$ instead of $\mathrm{HCl}$ & 4.5 \\
\hline
\end{tabular}

Figure 2 is representative of the sample after this first cycle of oxidation-annealing, there remains a significant amount of carbon nanoparticles. Removing the remaining residual catalyst metal impurity from the SWCNT is challenging, since the metal is usually encapsulated by a stable carbon coating which hinders the access of chemicals to the metal.

The major weight loss observed was at the secondary annealing at $350{ }^{\circ} \mathrm{C}$ (Tab. 1). At this temperature most of the carbonaceous matter, including many of the nanotubes, were eliminated. An SEM image of the sample at this stage after passing through a reflux process in $4 \mathrm{M}$ $\mathrm{HCl}$ is shown in Figure 3. The sample can be seen to be purer than that at $250{ }^{\circ} \mathrm{C}$, however, some impurities are still present indicating the need for further purification.

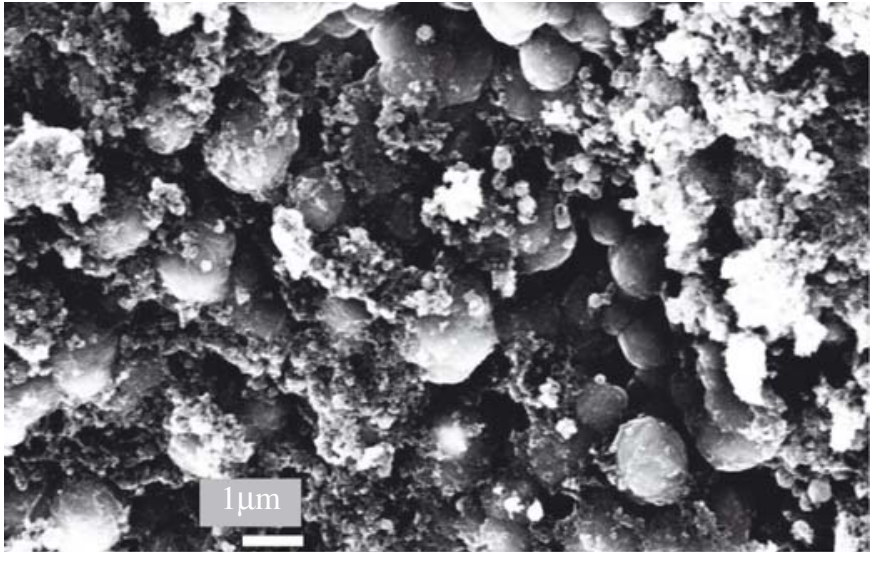

Fig. 4. SEM image of sample after third annealing at $450{ }^{\circ} \mathrm{C}$ and reflux with $4 \mathrm{M} \mathrm{HCl}$ showing the destruction of SWCNTs (Final product 1).

Further examination of the effect of annealing temperature on the purification process using successive annealing and refluxing with $4 \mathrm{M} \mathrm{HCl}$ was done by implementing a third annealing step at $450{ }^{\circ} \mathrm{C}$. This did not result in improved purity since the sample is thermally degraded as a consequence of the high temperature and prolonged exposure to acids. The SEM image of these tubes indicates that the SWCNTs were seriously damaged and destroyed as shown in Figure 4. There are several factors that contributed to the loss and destruction of SWCNTs:

1. The exothermic nature of the oxidation process makes it difficult to accurately control the temperature of the SWCNT inside the annealing bath, and indeed some nanotube material was seen burning off.

2. The presence of encapsulated metal catalysts aggravate the oxidation reaction, thus SWCNTs are observed to be completely destroyed to amorphous carbon at lower temperature than their oxidizing temperature.

Since it is not clear from the SEM images after this third step whether any nanotubes remain, we repeated the purification procedure but after the third annealing and acid reflux cycle we treated the sample with SDS (Procedure 2). SDS is known to render nanotubes soluble in water and thus provides a route to extract any remaining tubes from the mixture. This will then exclude the metallic nanoparticles so that they will get washed easily by water. The mixture was sonicated for $5 \mathrm{~h}$ at low power using a horn sonicator to improve dispersion. Although a good dispersion was observed visually in the solution, the final results were still destroyed SWCNTs with smaller yield $\sim 10 \%$ of the initial raw sample, as shown in Table 2 . The weight losses at $250{ }^{\circ} \mathrm{C}$ and $350{ }^{\circ} \mathrm{C}$ are due to oxidation of most carbonaceous impurities to oxides of carbon ( $\mathrm{CO}$ and $\mathrm{CO}_{2}$ ) and oxidation of the metal to metal chlorides, similar to the previous procedure. The additional weight loss observed as compared to Procedure 1 is due to the removal of metallic oxide impurities. However the nanotubes were totally distorted due to increased temperature and prolonged sonication power, as shown in Figure 5. 
A. Yaya et al.: Purification of single-walled carbon nanotubes

Table 3. Numerical values of the D and G-bands of raw and purified SWCNTs retrieved from their respective Raman spectra.

\begin{tabular}{ccccc}
\hline Raman band & & Frequency $\left[\mathrm{cm}^{-1}\right]$ & Intensity ratio $\left(I_{D} / I_{G}\right)$ & $\mathrm{FWHM}\left[\mathrm{cm}^{-1}\right]$ \\
\hline \multirow{2}{*}{ Raw-SWCNTs } & $\mathrm{D}$ & 1294 & 0.100 & 83 \\
& $\mathrm{G}$ & 1583 & & - \\
Purified SWCNTs (P3) & $\mathrm{D}$ & 1295 & 0.037 & - \\
& $\mathrm{G}$ & 1591 & & - \\
\hline
\end{tabular}

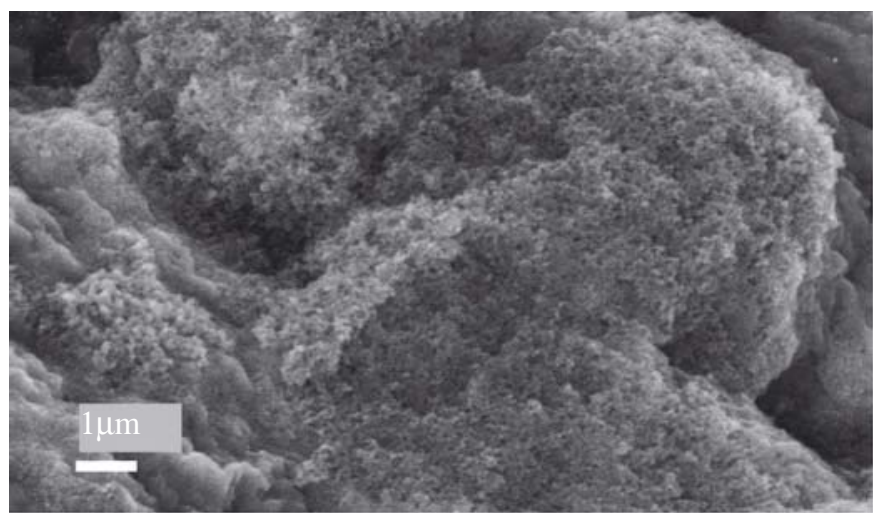

Fig. 5. SEM image of SWCNTs after Procedure 2 (described in the text) showing the nanotubes have primarily been converted to amorphous carbon (Final product 2).

We note that in all the purification processes sample holder size plays a significant role in controlling the oxidizing temperature. The larger the container, the more controlled the oxidation, since the increased available volume allows heat liberation from the sample surface, avoiding burning of nanotubes due to exothermic reaction.

In light of the above results, a new two annealing step purification method (Procedure 3) was developed. In this method, a first annealing step at $300{ }^{\circ} \mathrm{C}$ removes significant amount of amorphous carbon and subsequent acid treatment in $6 \mathrm{M} \mathrm{HCl}$ removes the metal catalysts. This is followed by a second oxidation step at $350^{\circ} \mathrm{C}$ which cracks and fractures the encapsulates of the metal nanoparticles. This exposes encapsulated metal particles for the final acid treatment which almost removes most of the metal catalyst. The process yields SWCNTs of good purity, as shown qualitatively in the EDS spectra (Fig. 6).

By limiting the oxidation temperature to $350{ }^{\circ} \mathrm{C}$ we ensure minimal loss of carbon nanotubes. As a result, the final yield after purification reaches $\sim 26 \%$, see Table 2. Figure 6 shows a representative SEM image of resultant SWCNTs showing their high purity and lack of large scale damage as compared to the previous procedures. We further analyse the product from Procedure 3 using Raman spectroscopy, SEM coupled with EDS and thermo-gravimetrics.

In Figure 7 the Raman spectra of the raw and purified SWCNTs are shown. The G-band is an indication of the graphitic quality of the sample while the D-band is normally taken as an indication of degree of disorder. The full-width-half-maxima (FWHM) of the D-band is an indication of the amount of carbonaceous impurities.

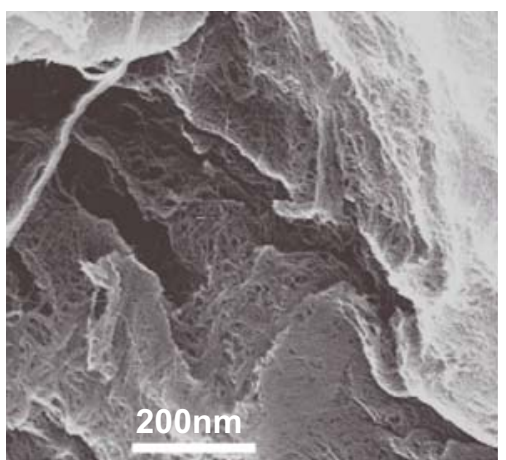

(a)

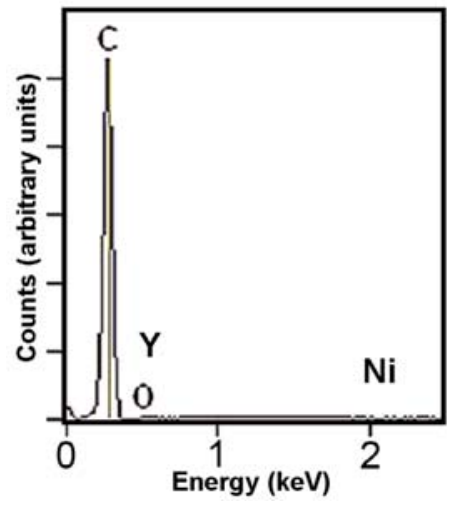

(b)

Fig. 6. (a) Representative SEM image of SWCNTs purified following Procedure 3 (see text), showing relatively high purity compared with the previously described purification routes. (b) EDS of the purified sample showing low metallic impurity content as compared to the raw sample in Figure 1 (final product 3$)$.

The sample quality (defect density) can be checked by comparing the D to G-band Raman intensity. These are given for the raw and purified samples in Table 3. The $D$ to $G$ peak intensity ratio drops by a factor of nearly three on purification, while the D peak FWHM drops by $43 \%$, confirming the improved purity after treatment. This behaviour in the peak intensity is quite typical for acid treated tubes in which the peak originating from metallic tubes decreases when the tubes are acid treated due to a loss of continuum states as a result of functionalisation of the tubes compared to the raw tubes. This change has also been reported elsewhere [29]. This loss of broad BreitWigner-Fano feature has also been ascribed to debundling of the tubes [30] which could occur during our purification 

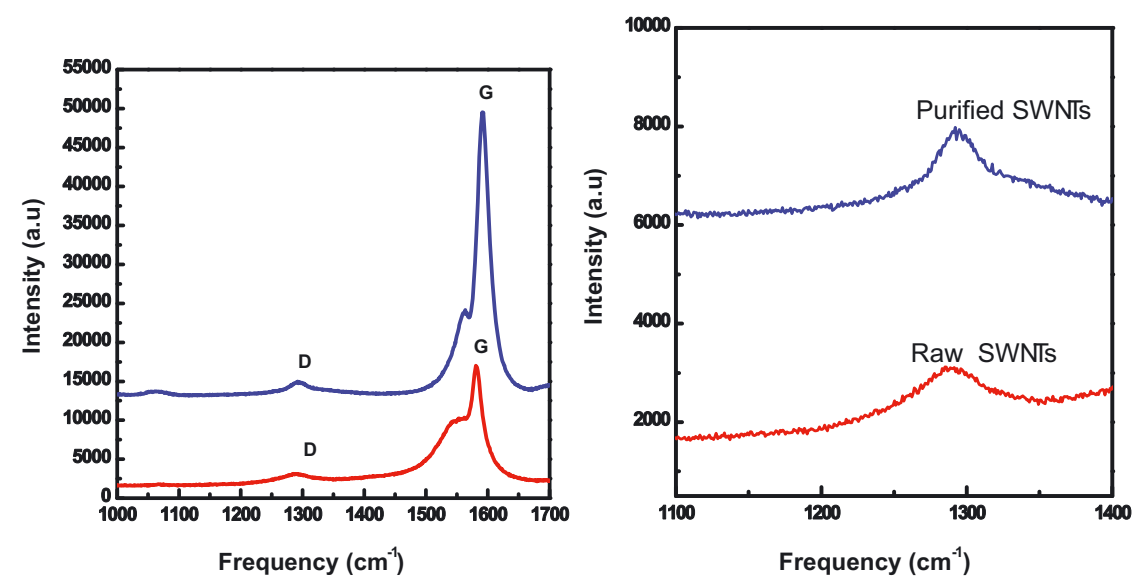

Fig. 7. (Color online) Raman spectra for raw (red, lower) and treated (blue, higher) SWCNTs. Right hand figure shows a zoom of the D-band.

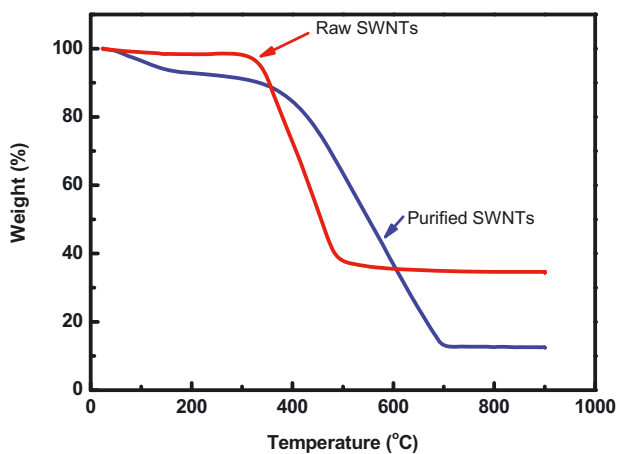

Fig. 8. (Color online) TG curves for raw and purified SWCNTs obtained at a heating rate of $10{ }^{\circ} \mathrm{C} / \mathrm{min}$.

procedure as the nanotube surfaces become functionalised and charged during acid treatment.

There remains a small D peak contribution, probably due to the presence of tube defect introduced by the acid treatment. Dillon et al. [31] found that the D/G intensity ratio never fell below 0.005 for purified samples.

Thermo-gravimetric analysis (TGA) and differential thermo-gravimetric (DTG) studies of the raw and treated samples were performed to assess the composition with respect to metals, SWCNTs, and other carbonaceous species. Since the gas flow used is air, we assume that when heating, all the carbon and metals are converted to their corresponding oxides.

The TG curves of both raw and purified SWCNTs are presented in Figure 8, with corresponding DTG curves in Figure 9. The sharp weight loss of the raw SWCNTs commencing at $\sim 300{ }^{\circ} \mathrm{C}$ is due to oxidation of excess carbonaceous material. This weight loss extends to $470{ }^{\circ} \mathrm{C}$ leaving an overall weight residue of $\sim 32 \%$ in the crucible consisting largely of $\mathrm{Y}, \mathrm{Ni}$ and Co catalyst particles. The treated material has a lower weight residue of $\sim 12 \%$, showing the importance of acid treatment after the first step of gas phase oxidation for catalyst removal. The different structural forms of carbon exhibit different reactivity towards oxidation. In general the purified tubes break down at a higher temperature than the amorphous carbon which can be seen by the higher weight loss onset temperature for the purified sample $\left(350-400{ }^{\circ} \mathrm{C}\right)$, consistent with previous reports $[13,32,33]$. The corresponding most rapid weight loss observed in the DTG curve for the purified sample (Fig. 9b) at $\sim 540{ }^{\circ} \mathrm{C}$ shows an upshift of $\sim 170{ }^{\circ} \mathrm{C}$ compared to the raw SWCNTs. This is evidence for the thermal stability of purified SWCNTs and confirms that the purification procedure depletes most of the amorphous carbonaceous structures present in the as-prepared SWCNT sample. This is nonetheless lower than literature temperatures for thermal degradation of undamaged SWCNTs $\left(\sim 660{ }^{\circ} \mathrm{C}\right)[34]$, consistent with the Raman data indicating that the nanotubes contain a fraction of defects and functional groups attached to the side (end) walls. Hence, these nanotubes are oxidize at lower temperature $\left(\sim 550^{\circ} \mathrm{C}\right)$ than the less defective SWCNTs.

The sharp drop in the DTG at $\sim 110{ }^{\circ} \mathrm{C}$ for the treated sample, and the observed continuous weight loss from room temperature and above in the TGA, is due to loss of water molecules. These we tentatively ascribe to breakdown and loss of $-\mathrm{COOH}$ groups introduced during the acid treatment, as well as the loss of residual water which will be hydrogen bonded to the hydrophilic $-\mathrm{COOH}$ surface groups on the tube surfaces and trapped in the bundles.

\section{Conclusions}

We have examined several oxidation methods to purify single-walled carbon nanotubes produced by the arcdischarge method. After analysing the purity using SEM, EDS, TGA and Raman spectroscopy, we found that a twoannealing step purification procedure where the sample is oxidised in air at $300{ }^{\circ} \mathrm{C}$ and $350{ }^{\circ} \mathrm{C}$ with subsequent acid treatment in $6 \mathrm{M} \mathrm{HCl}$ gave samples which were a good compromise between reasonably high purity and good yields $(>25 \%)$, albeit with some surface defects introduced on the walls of nanotubes. In addition the process has the added advantage of being less time consuming 


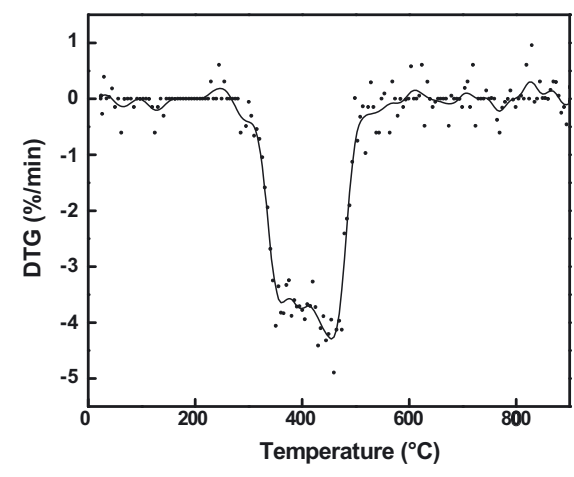

(a)

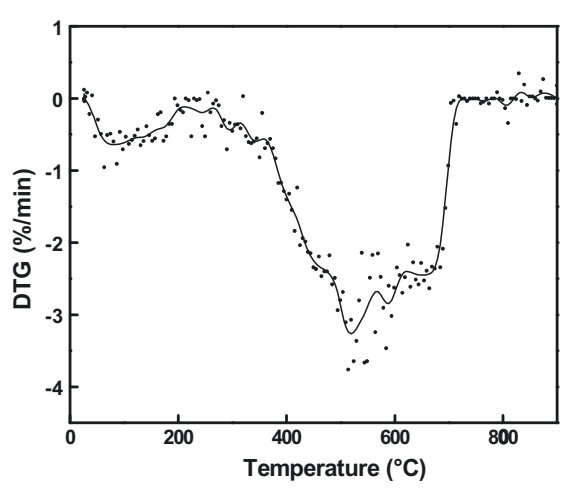

(b)

Fig. 9. (Color online) DTG curves obtained at a heating rate of $10^{\circ} \mathrm{C} / \mathrm{min}$ for the (a) raw and (b) purified SWCNTs (curves are FFT fit to the data as a guide to the eye).

(complete in $4.5 \mathrm{~h}$ ) than conventional acid purification methods which require significantly more than $5 \mathrm{~h}$.

A. Yaya and A.G. Tekley acknowledge support from the European Commission for funding under the Erasmus Mundus scheme.

\section{References}

1. S. Iijima, T. Ichihashi, Nature 363, 603 (1993)

2. C. Niu, E.K. Sichel, R. Hoch, D. Moy, H. Tennent, Appl. Phys. Lett. 70, 1480 (1997)

3. L. Diederich, E. Barborini, P. Piseri, A. Podesta, P. Milani, A. Schneuwly, R. Gallay, Appl. Phys. Lett. 75, 2662 (1999)

4. G.T. Wu, C.S. Wang, X.B. Zhang, H.S. Yang, Z.F. Qi, P.M. He, W.Z. Li, J. Electrochem. Soc. 146, 1696 (1999)

5. E. Franckowiak, S. Gautier, H. Gaucher, S. Bonnamy, F. Beguin, Carbon 37, 61 (1999)

6. A.M. Cassel, J.A. Raymakers, J. Kong, H. Dai, J. Phys. Chem. B 103, 6484 (1999)

7. C. Journet, W.K. Maser, P. Bernier, A. Loiseau, M. Lamy de la Chapelle, S. Lefrant, P. Daniard, R. Lee, J.E. Fischer, Nature 388, 756 (1997)

8. Y. Saito, Y. Tani, N. Miyagawa, K. Mitsushima, A. Kasuya, Y. Nishina, Chem. Phys. Lett. 294, 593 (1998)

9. Z.J. Shi, Y.F. Lian, X.H. Zhou, Z.N. Gu, Y. Zhang, S. Iijima, L.X. Zhou, K.T. Yue, S.L. Zhang, Carbon 37, 1449 (1999)

10. T. Guo, P. Nikolaev, A. Thess, D.T. Colbert, R.E. Smalley, Chem. Phys. Lett. 49, 243 (1995)

11. T.W. Ebbesen, P.M. Ajayan, H. Hiura, K. Tanigaki, Nature 367, 519 (1994)

12. I.W. Chiang, B.E. Brinson, R.E. Smalley, J.L. Margrave, R.H. Hauge, J. Phys. Chem. B 105, 1157 (2001)

13. P.-X. Hou, C. Liu, H.-M. Cheng, Carbon 46, 2003 (2008)

14. Z.J. Shi, Y.F. Lian, F.H. Liao, X.H. Zhou, Z.N. Gu, Y. Zhang, S. Iijima, Solid State Commun. 35, 112 (1999)

15. K. Tohji, H. Takahashi, Y. Shinoda, N. Shimizu, B. Jeyadevan, I. Matsuoka, Y. Saito, A. Kasuya, S. Ito, Y. Nishina, J. Phys. Chem. B 101, 1974 (1997)

16. B. Liu, T. Wagberg, E. Olssen, R. Yang, H. Li, S. Zhang, H. Yang, G. Zou, B. Sundqvist, Chem. Phys. Lett. 320, 365 (2000)
17. S. Bandow, A.M. Rao, K.A. Williams, A. Thess, R.E. Smalley, P.C. Ecklund, J. Phys. Chem. B 101, 8839 (1997)

18. K.B. Shelimov, R.O. Esenaliev, A.G. Rinzler, C.B. Huffman, R.E. Smalley, J. Chem. Phys. Lett. 282, 429 (1998)

19. A. Yu, E. Bekyarova, M.E. Itkis, D. Fakhrutdinov, R. Webster, R.C. Haddon, J. Amer. Chem. Soc. 128, 9902 (2006)

20. W. Li, Y. Bai, Y. Zhang, M. Sun, R. Cheng, X. Xu, Y. Chen, Y. Mo, Synth. Met. 155, 509 (2005)

21. J.-M. Moon, K.H. An, Y.H. Lee, Y.S. Park, D.J. Bae, G.-S. Park, J. Phys. Chem. B 105, 5677 (2001)

22. P.X. Hou, S. Bai, Q.H. Yang, C. Liu, H.M. Cheng, Carbon 40, $81(2002)$

23. U. Chen, M.L.H. Green, J.L. Griffin, J. Hammer, R.M. Lago, S.C. Tsang, Adv. Mater. 8, 1012 (1996)

24. J.L. Zimmerman, R.K. Bradley, C.B. Huffman, R.H. Hauge, J.L. Margrave, Chem. Mater. 12, 1361 (2000)

25. P.J.F. Harris, Carbon Nanotube Science (Cambridge University Press, New York, 2009)

26. V. Georgakilas, D. Voulgaris, E. Vazquez, M. Prato, D.M. Guldi, A. Kukovecz, H. Kuzmany, J. Am. Chem. Soc. 124, 14318 (2002)

27. http://www. carbolex.com/products.html

28. Z. Zhao, H. Hu, S. Niyogi, M.E. Itkis, M.A. Hamon, P. Bhowmik, M.S. Meier, R.C. Haddon, J. Am. Chem. Soc. 123, 11673 (2001)

29. G.S. Duesberg, S. Roth, P. Downes, A. Minett, R. Graupner, L. Ley, N. Nicoloso, Chem. Mater. 15, 3314 (2003)

30. C. Jiang, K. Kempa, J. Zhao, U. Schlecht, U. Kolb, T. Basché, M. Burghard, A. Mews, Phys. Rev. B 66, 161404(R) (2002)

31. A.C. Dillon, T. Gennett, K.M. Jones, J.L. Alleman, P.A. Parilla, M.J. Heben, Adv. Mater. 11, 1354 (1999)

32. J.P.C. Triguerio, G.G. Silva, R.L. Lavall, C.A. Furtado, S. Oliveira, A.S. Ferlauto, R.G. Lacerda, L.O. Ladeira, J.-W. Liu, R.L. Frost, G.A. George, J. Nanosci. Nanotech. 7, 3477 (2007)

33. R.B. Mathur, S. Seth, C. Lal, R. Rao, B.P. Singh, T.L. Dhami, A.M. Rao, Carbon 45, 132 (2007)

34. http://www.msel.nist.gov/Nanotube2/ Practice\%20Guide_Section\%202_TGA.pdf 